\title{
PROTEÇÃO À SAÚDE DO TRABALHADOR, MONETIZAÇÃO DOS RISCOS E O NOVO CÓDIGO DE PROCESSO CIVIL
}

\section{PROTECTING THE WORKER'S HEALTH, MONETIZATION OF THE HAZARDS AND THE NEW CODE OF CIVIL PROCEDURE}

Thiago Ribeiro de Carvalho ${ }^{1}$ Judith Aparecida de Souza Bedê ${ }^{2}$

\section{RESUMO}

O presente artigo aborda a necessidade de se combater preventivamente os riscos à saúde e à integridade física do trabalhador e a necessidade da prestação judicial célere. A pesquisa foi realizada com a análise dos textos legais e da doutrina especializada. Iniciou-se pelo exame do princípio da inafastabilidade do poder judiciário, especialmente em relação à ameaça de lesão à saúde e à integridade física do trabalhador. Na sequência, foram analisadas as tutelas de urgência previstas no Novo Código de Processo Civil e a possibilidade de sua utilização em prol do trabalhador.

Palavras-chave: Prevenção. Integridade física. Danos à saúde.

\begin{abstract}
This article approaches the need to fight preventively health hazards and risks to the physical integrity of the worker and the need of speedy judicial provision. The research was made through an analysis of legal texts and specialized doctrine. It was initiated by the principle of non-obviation exam, especially when it is in cases of injury threats and risks to the physical integrity of the worker. Furthermore, the emergency guardianships, read in the New Code of Civil Procedure, and the possibility of its use on the worker's benefit.
\end{abstract}

Keywords: Prevention; Physical integrity; Health Hazards

1 - Doutorando em Direito pela Faculdade Autônoma de Direito - FADISP de São Paulo, (Brasil). Mestre em Direito Processual Civil pela PUC Minas, Especialista em Direito Processual, Advogado militante e professor da Nova Faculdade de Contagem-MG.

2 - Doutoranda em Direito pela Faculdade Autônoma de Direito de São Paulo - FADISP, (Brasil). Professora do Curso de Direito da FAFIMAN e de Pós-graduação em Maringá e região. E-mail: judithbede@gmail.com 


\section{SUMÁRIO}

Introdução; 1. O direito do trabalho e o seu enquadramento como direito privado; 2. O livre acesso ao judiciário e a necessidade de prevenção; 3. A monetização do direito versus prevenção; 4.Celeridade processual e garantias constitucionais; 4.1. A agilidade necessária; 5. A tutela de urgência preventiva no direito do trabalho; 5.1. Perigo de dano ou risco ao resultado útil do processo e probabilidade do direito; 5.2. Liminar sem a oitiva da parte contrária; 6.Conclusão; Referências.

\section{INTRODUÇÃO}

O objetivo deste trabalho é abordar a necessidade da proteção jurídica à saúde do trabalhador por meio de medidas judiciais e legislativas. A pesquisa se justifica diante do alto número de funcionários que desenvolvem doenças a partir do labor em condições nocivas a sua saúde. Em relação à prestação jurisdicional, foi analisada a importância de esta ser tempestiva e útil.

A investigação iniciou-se esclarecendo que o direito do trabalho está inserido no direito privado, sendo tal condição essencial para a abordagem da responsabilidade do empresário em relação à proteção da saúde do trabalhador. Na sequência, será tratado o acesso ao poder judiciário e a necessidade de uma tutela jurisdicional tempestiva, a qual pode ser alcançada por meio da tutela de urgência cautelar.

Ao final deste artigo pretende-se demonstrar os posicionamentos divergentes a respeito do tema, ampliar o debate, tornar-se uma fonte de pesquisa para os interessados no tema e alinhar as formas possíveis de proteção à saúde do trabalhador por meio do Novo Código de Processo Civil.

\section{O DIREITO DO TRABALHO E O SEU ENQUADRAMENTO COMO DIREITO PRIVADO}

Inicialmente, cumpre destacar que não se ignora a divergência referente à classificação do direito do trabalho entre público, privado ou como um terceiro gênero. No entanto, este trabalho foi desenvolvido a partir da premissa de que o direito do trabalho se encontra no âmbito do direito privado. 
Enfocada a substância nuclear do Direito do Trabalho (relação de emprego) e seu cotejo comparativo com a substância dos demais ramos jurídicos existentes, não há como escapar-se da conclusão de que o ramo justrabalhista situa-se no quadro componente do direito privado (DELGADO, 2006, p. 74).

Esse esclarecimento de fundo é necessário para prosseguir com o desenvolvimento do artigo, visto que o objetivo é analisar as relações das sociedades empresárias com os trabalhadores e as medidas adotadas pelo poder público pertinente à saúde do trabalhador. Consequentemente, há de se perquirir qual a postura do Estado em relação ao tema e quais são as atuações dos agentes estatais, a saber: parlamentares, magistrados e Ministério Público do Trabalho.

\section{O LIVRE ACESSO AO JUDICIÁRIO E A NECESSIDADE DE PREVENÇÃO}

$\mathrm{O}$ artigo $5^{\circ}$, inciso $\mathrm{XXXV}$, da Constituição Federal garante o livre acesso ao judiciário ao afirmar que a lei não poderá excluir da apreciação do judiciário, lesão ou ameaça de lesão a direitos. Ao analisar esse dispositivo constitucional, vislumbra-se que o legislador constitucional impôs restrições ao legislador infraconstitucional, ou seja, proibiu-o de criar empecilhos para o acesso ao poder judiciário.

\footnotetext{
A melhor leitura do referido dispositivo constitucional, na sua qualidade de garantia constitucional fundamental, é a que a lei [legislador], o particular, e o próprio órgão jurisdicional não poderão excluir da apreciação do Poder Judiciário a afirmação de ameaça a direitos em geral [individuais ou coletivos] (ALMEIDA, 2008, p. 253).
}

Especificamente em relação ao direito do trabalho, a prevenção do dano ganha destaque, devido às características do objeto discutido (saúde do trabalhador e integridade física) e à dificuldade ou até mesmo impossibilidade de reparação do dano.

Com a promulgação da Constituição de 1988, ocorreu uma mudança de paradigma, e o trabalhador assumiu uma nova posição frente ao Estado, proporcionada pelo modelo democrático e pelas garantias fundamentais. Consequentemente, a atividade judicial também sofreu modificações para concretizar essas conquistas (SERBENA, 2004, p. 121). 
Nesse contexto, a tutela preventiva no âmbito trabalhista ganha destaque para resguardar o bem jurídico em questão, ou seja, a vida, a saúde e a integridade física do trabalhador. Note-se que a importância da prevenção reside na dificuldade de se restabelecer a saúde do trabalhador que por muitos anos laborou em condições insalubres, ou então na impossibilidade de devolver-lhe a vida em caso de óbito decorrente do labor em atividades perigosas.

\section{A MONETIZAÇÃO DO DIREITO VERSUS PREVENÇÃO}

O direito brasileiro parece caminhar para a valorização da reparação monetária em detrimento da busca por mecanismos de prevenção, visto que, nos últimos anos, o legislador atuou pouco para minimizar os riscos do trabalho em condições lesivas à saúde do trabalhador brasileiro.

Por sua vez, o constituinte tratou do tema no artigo $7^{\circ}$, incisos IX, XIII, XIV e XVI, os quais balizam a realização do trabalho noturno, das horas extras e de turnos de revezamento, impondo algumas restrições para o seu desenvolvimento.

No tocante ao trabalho noturno ou em turnos de revezamento, o desgaste é consequência da alteração do relógio biológico do trabalhador. O ideal seria não permitir o trabalho nessas condições, entretanto, diante da necessidade de algumas atividades, é plausível que sejam tomadas medidas para minimizar esses efeitos (ANDRADE, 2003, p. 36). Em sentido complementar, Maciel Júnior (1998, p. 228) propõe a redução da jornada de trabalho para seis horas, como forma de prevenir danos à saúde do trabalhador.

Apesar de bem-intencionada, a proposta de redução da jornada de trabalho não foi fundamentada em estudos científicos. Por esse motivo, o ideal seria a realização de estudos interdisciplinares com o intuito de averiguar quais medidas são necessárias para preservar a saúde do trabalhador.

No mesmo norte, parece ser pertinente proibir a adoção dos turnos ininterruptos de revezamento e de trabalho noturno para as atividades não essenciais. Também seria de grande valia impedir que o indivíduo tivesse mais de um emprego, ante uma possível redução da jornada de trabalho. 
Certamente, tais medidas contribuiriam de forma significativa para a preservação da saúde e da integridade física do trabalhador. Além da adoção de tais medidas, seria de bom alvitre instituir um controle periódico para aferir possíveis alterações na saúde do trabalhador.

Em relação às horas extras, o constituinte, ao limitar a jornada de trabalho, indubitavelmente demonstrou interesse em preservar a saúde do trabalhador, ou seja, tal dispositivo deve ser interpretado como uma forma de desestimular a realização de trabalho em horas extraordinárias, por meio da fixação de percentual de remuneração superior ao da hora de trabalho normal.

No tocante aos adicionais de insalubridade e periculosidade, estes parecem ser os mais perversos, por permitirem que se afete de maneira contundente a saúde do trabalhador, a ponto de serem causadas sequelas irreparáveis, mediante o recebimento de adicionais irrisórios.

Ademais, é possível encontrar diversos registros de acidentes de trabalho, decorrentes do perigo inerente à atividade, e a monetização da insalubridade acomete o indivíduo de doenças profissionais ou do trabalho (OLIVEIRA, 2011, p.153).

Indiscutivelmente, a legislação trabalhista possibilita claramente ao empregador pagar um adicional de insalubridade ou periculosidade pífio, o qual é insuficiente para "indenizar" o trabalhador pelo risco a sua saúde e sua integridade física.

Assim, conclui-se que o labor nas condições supramencionadas são extremamente lesivas à saúde do trabalhador e que o respectivo adicional é insuficiente para tornar indene o dano. Certamente, a interpretação adequada de tais dispositivos deveria ser no sentido de que os adicionais desmotivassem o trabalho nessas condições, ou como forma de incentivar o empregador a eliminar o dano à saúde do trabalhador. Ocorre que, para tanto, seria necessária a mudança da legislação pertinente, para majorar os percentuais existentes, como forma de incentivar o empregador a eliminar os agentes nocivos ao trabalhador.

Entretanto, constata-se que o Estado também contribui para a monetização dos danos, ao possibilitar a realização de Termos de Ajustes de Condutas, os quais permitem ao empregador continuar por um período causando danos à saúde do empregado ou mesmo colocando a sua integridade física em risco.

A título de exemplo, é possível citar o ocorrido na cidade de Santo Antônio do Monte, onde foi realizado um termo de ajuste de conduta para que determinada empresa adotasse, no prazo de 1(um) ano, as medidas para evitar explosões em uma fábrica de foguetes. Ocorre que durante a vigência do termo de ajuste de conduta houve uma explosão e 
seis funcionárias morreram. Certo é que o funcionamento de forma irregular, com a chancela do Ministério Público do Trabalho, culminou na morte de trabalhadoras, ou seja, um dano irreparável.

Na situação descrita, parece clara a necessidade de se evitar o dano em um primeiro momento (fechamento da fábrica), para salvaguardar a saúde, a vida e a integridade física dos trabalhadores.

O exemplo citado é útil para demonstrar a importância da tutela preventiva na defesa do direito do trabalhador, cuja tutela de urgência cautelar ganha uma importância ainda maior diante da dificuldade de reparação do dano ou mesmo da sua irreparabilidade.

Sem dúvida, o foco deve ser combater a "quantificação do risco" na jornada noturna, em revezamento, nas horas extras, na realização de trabalhos perigosos ou insalubres, tendo em vista que há um prejuízo à saúde do trabalhador. Aceitar um "adicional" que tenha por objetivo "indenizar" o trabalhador consiste em quantificar monetariamente a saúde e a vida do indivíduo (OLIVEIRA, 2011, p. 155).

É notório que o empresário raciocina e toma as suas decisões com base na redução de custos e no aumento dos lucros, e a eliminação do risco é mais onerosa ao empregador, sendo então mais "vantajoso" pagar o adicional.

Todavia, é inadmissível que o Estado se mantenha inerte ou chancele a conduta de sobreposição da liberdade de empreender ao direito do trabalhador à saúde e à integridade física. Nesse sentido, quando for possível a eliminação do risco, é necessário que este seja reduzido, para que haja a minimização do risco onerado (OLIVEIRA, 2011, p.164).

O que não se pode admitir é a banalização da saúde do trabalhador, conforme ocorre em alguns acordos ou convenções coletivas, nas quais os sindicatos aceitam que os trabalhadores se submetam a condições que poderiam ser eliminadas por investimento ou minimizadas pela diminuição do número de horas trabalhadas.

A minimização do risco deve ser priorizada, quando não for possível eliminá-lo em razão da importância da atividade executada pelo trabalhador. Entretanto, no que tange aos riscos que podem ser eliminados por meio de investimentos, não se pode permitir que o interesse empresarial se sobreponha ao direito, à saúde e à dignidade da pessoa humana, resguardados pela Constituição.

Posteriormente à análise das situações acima, constata-se que os ditames trabalhistas privilegiam a monetização dos danos à saúde e à integridade física do empregado, em 
detrimento da adoção de meios preventivos. Verifica-se na Consolidação das Leis do Trabalho a obrigação de pagar o adicional de insalubridade e o adicional de periculosidade, o que permite a leitura dos dispositivos da seguinte forma: o empregador pode submeter o empregado à realização de trabalhos que coloquem em risco a sua saúde e a sua integridade física desde que pague o adicional prescrito em lei.

\section{CELERIDADE PROCESSUAL E GARANTIAS CONSTITUCIONAIS}

Diante dos bens jurídicos em questão (vida, saúde e integridade física), é necessário que o Estado-Juiz responda tempestivamente à demanda submetida. A busca por uma técnica capaz de equacionar o respeito às garantias do cidadão com a celeridade processual tem sido objeto de estudo dos processualistas ao longo dos anos.

Verifica-se que a intenção de encontrar uma decisão judicial célere ${ }^{3}$ e em consonância com as garantias constitucionais processuais tem sido um grande desafio para os processualistas. Ocorre que, com o advento da Emenda Constitucional n. 45/2004, a celeridade processual foi alçada ao patamar de direito fundamental e, por esse motivo, a busca dessa celeridade ganhou novos contornos.

Ao tratar do tema, Maciel Júnior (2012, p. 1) afirma que “[...] a celeridade tem por objetivo assegurar que haja um limite e não se eternize a discussão no processo, garantindo, de preferência, uma resposta rápida ao litígio".

Segundo Marinoni (1996, p. 27), na história do processo ainda não foi encontrada uma forma de resolver o litígio de forma célere sem afrontar direitos dos jurisdicionados. Enquanto isso, a morosidade aniquila direitos e muitas vezes serve a propósitos escusos dos detentores do poder.

Em um primeiro momento, é necessário verificar quais os fatores que contribuem para a letargia da atividade judicial. Marinoni (1996, p. 28) analisa a questão sob duplo vértice: a estrutura do judiciário; e a técnica processual. Em relação ao primeiro, o doutrinador propõe que haja uma relação adequada entre o número de juízes e o número de processos. Já em relação ao segundo, afirma que a universalização do procedimento ordinário contribui para a letargia do judiciário.

\footnotetext{
${ }^{3}$ No direito italiano, conferir Il tempo e il processo de Ítalo Andolina (2009, p. 259-274).
} 
[...] a lentidão do processo pode transformar o princípio da igualdade processual, na expressão de Calamandrei, em "coisa irrisória”. A morosidade gera a descrença do povo na justiça; o cidadão se vê desestimulado de recorrer ao Poder Judiciário quando toma conhecimento da sua lentidão e dos males (angústias e sofrimentos psicológicos) que podem ser provocados pela morosidade judicial (MARINONI, 1996, p. 32).

A proposta de Marinoni para o alcance da celeridade processual refere-se à elaboração de uma pluralidade de procedimentos adequados que atendam às necessidades do direito material para a solução dos litígios. Dessa forma, seria possível assegurar as garantias constitucionais processuais sem, contudo, prolongar indevidamente a marcha processual.

Em sentido diferente, Dias (2010, p. 162) sustenta que a agilidade processual pode ser comprometida pela "complexidade das questões discutidas, pelo comportamento das partes e pela atuação dos órgãos jurisdicionais".

Como foi dito, a busca da celeridade não pode afrontar as garantias concedidas pela Carta Magna. Para Grinover (1975, p. 5), o processo constitucional exige a observância dos direitos fundamentais, da organização judiciária, do processo e da jurisdição constitucional.

Segundo a jurista, o processo deve abranger o princípio do devido processo legal, as garantias processuais individuais e a inafastabilidade do poder judiciário. Em sentido diferente, Dias (2006, p. 655) entende que a busca pela celeridade deve observar o princípio do devido processo legal, que consiste em:

[...] um bloco aglutinante e compacto de várias garantias fundamentais que são: a) direito ao amplo acesso à jurisdição, prestada dentro de um tempo útil ou lapso temporal razoável; b) garantia do juízo natural; c) garantia do contraditório; d) garantia de plenitude de defesa, com todos os recursos a ela (defesa) inerentes, aí incluído o direito ao advogado ou defensor público (art. 133 e 134); e) garantia da fundamentação racional das decisões jurisdicionais (art. 93, incisos IX e X); garantia de um processo sem dilações indevidas.

Diante disso, conclui-se que a técnica e a estrutura judicial não podem afrontar as garantias constitucionais processuais. Desse modo, no Estado Democrático de Direito a celeridade deve ser buscada por meio de um processo sem dilações indevidas.

Sem dúvida, uma das técnicas utilizadas para assegurar a celeridade e a efetividade do processo é a adoção das tutelas de urgência, as quais podem ser utilizadas para garantir a efetividade do processo ou mesmo para antecipar a satisfatividade da pretensão em litígio. 


\subsection{A AGILIDADE NECESSÁRIA}

Com o intuito de alcançar um processo célere, eficiente e com menores custos, diversos processualistas se debruçaram sobre o tema ao longo dos anos. O grande desafio consiste em conseguir conjugar a observância das garantias constitucionais processuais com a elaboração de um processo ágil e eficiente.

No século XIX, alguns países que compõem a Europa passaram por movimentos reformistas, e a adoção da oralidade se disseminou no Velho Continente. Nessa esteira, o direito italiano passou por reformas processuais com o fim da Segunda Guerra Mundial. Com o intuito de debelar a morosidade judicial, Chiovenda foi nomeado relator de uma comissão que possuía a incumbência de solucionar a letargia judicial.

Os estudos da oralidade e da concentração dos atos em audiência nortearam os trabalhos, no entanto o modelo oral não foi adotado devido à influência das reformas processuais da Europa no século XIX, mas sim à própria tradição do processo penal italiano (CHIOVENDA, 1940, p. 39-40).

Os integrantes da comissão acreditavam que a criação de uma técnica processual predominantemente oral, com a concentração dos atos em audiência, poderia resultar em um processo "justo", célere e eficaz.

O Brasil não ficou alheio ao debate acerca da morosidade judicial. $\mathrm{O}$ assunto foi debatido antes da redação do CPC de 1939. Os juristas da época procuraram detectar as falhas do sistema vigente e propuseram algumas soluções para alcançar uma justiça rápida e menos custosa.

$\mathrm{Na}$ época, predominavam três correntes doutrinárias, formadas pelos defensores do processo oral, do escrito e do misto.

Entre os adeptos do processo oral, encontrava-se Medeiros (1940, p. 69), que sustentava ser esta a única forma de se remediar "os males que afligem a justiça, cuja lentidão é a mais deplorável”. Aos críticos afirmava não se tratar de um total extermínio da forma escrita e o definia da seguinte forma:

[...] processo oral é uma expressão observada, uma fórmula concisa, comque significa que no desenrolar do movimento processual e na sua fase decisiva, a audiência de julgamento, predomina e prepondera a oralidade; na mesma fórmula se 
incluem uma série de consectários tão importantes como a própria oralidade ${ }^{4}$ (MEDEIROS, 1940, p. 69).

No mesmo sentido, Campos (1940, p. 15) classificava o processo escrito como dispendioso, antiquado, lento; e sustentava a adoção de um modelo de processo semelhante ao austríaco e ao alemão.

Já os defensores da manutenção do processo escrito invocavam a tradição e a falta de preparo dos brasileiros para a adoção de um padrão predominantemente oral (CAMPOS, 1940, p. 16).

Por fim, os adeptos da corrente mista sustentavam que a melhor alternativa era mesclar os modelos, sendo que na primeira instância, em regra, seria adotada a forma escrita e excepcionalmente o processo oral em algumas causas, enquanto na segunda instância predominaria a oralidade (GUIMARÃES, 1940, p. 16).

O ponto de convergência dos adeptos das três correntes citadas era que a atividade judicial no Brasil era cara, morosa, insegura e de resultados precários. Por isso, era necessário buscar soluções para essa realidade indesejada.

Pela defesa ferrenha do processo oral, destacava-se Campos (1940, p. 12),o qual mencionava que a época era marcada pelo aperfeiçoamento técnico dos instrumentos de trabalho e produção, enquanto a técnica de administração da justiça não se preocupava em se aprimorar. Segundo o autor, a solução para um processo judicial célere deveria ser baseada nos seguintes aspectos:

[...] em primeiro lugar reforma do ensino jurídico, dando maior envergadura e outras finalidades ao estudo do direito, transportando-o do plano da memorização e dos dogmas para o da investigação e da crítica [...]. Em segundo lugar, a organização racional do serviço legislativo, criando um centro de estudos, de informações e de investigações com a função de verificar as lacunas e defeitos do sistema jurídico, os vícios do seu funcionamento ou inadequações ou incompatibilidades do direito com as circunstâncias da vida ou das transformações operadas nos hábitos ou nos sentimentos públicos. Tanto a primeira como a segunda medida se resume simplesmente em tornar o direito permeável às transformações intelectuais operadas em todos os domínios da atividade científica e prática. O que se exige, em suma, é que o direito beneficie os métodos de apreciação e de estudo, que tornaram possíveis os rápidos progressos da medicina, dos processos industriais e o melhoramento ou a racionalização de todas as técnicas do trabalho humano ${ }^{5}$ (CAMPOS, 1940, p.13).

\footnotetext{
${ }^{4}$ Foi mantida a redação original.

${ }^{5}$ Foi mantida a redação original.
} 
Assim, o autor afirmava a necessidade de melhorar a organização, o aparelhamento e o controle da atividade judicial, com a finalidade de tornar a solução do conflito mais célere e precisa. Nesse contexto, os juristas teriam a função de contribuir com atividades construtivas e criadoras do direito por meio da crítica.

O modelo de processo oral proposto à época e adotado pelo CPC de 1939 era composto pelos seguintes elementos: a) a predominância da palavra falada; b) a imediatidade da relação do juiz com as partes e com os meios produtores de certeza; c) a identidade física do juiz; d) a concentração dos atos processuais; e) a irrecorribilidade das decisões interlocutórias. Na sequência, trata-se de cada um desses elementos:

a) predominância da palavra falada - não significa a exclusão de toda a escrita, porque seria impossível um processo puramente oral, diante da necessidade de se documentar as comunicações prévias antes da audiência, bem como de se registrar por escrito um resumo do depoimento das testemunhas para que não seja necessário colher o depoimento novamente (GUIMARÃES, 1940, p. 22). Segundo Chiovenda (1940, p.58), a oralidade não pode "contentar-se com uma discussão oral em audiência", sendo então viável a resolução dos incidentes processuais em audiência e a redução das formalidades dispensáveis, ou seja, potencializa-se a obtenção de um processo sem dilações indesejadas;

b) imediatidade da relação do juiz com as partes e com os meios produtores de certeza - consiste no "o contato pessoal do juiz com o perito e testemunhas. Esse contato direto do juiz permite que o magistrado forme a sua convicção de maneira plena e eficaz" (MORATO, 1940, p. 5). Em uma visão contemporânea, podemos citar Leite (2009, p. 416), que ao tratar do tema afirma o seguinte: "é o juiz, como diretor do processo, quem colhe, diretamente e imediatamente, a prova";

c) identidade física do juiz - vincula o juiz que realizou a fase instrutória a julgar a causa. Essa vinculação decorre da imediatidade da relação do juiz com os meios produtores de certeza;

d) concentração dos atos processuais - é sem dúvida o elemento mais importante do processo oral. Como se disse anteriormente, o processo francês era predominantemente oral, porém não havia a concentração dos atos processuais, sendo essa uma das causas de sua morosidade. O modelo oral não tem o condão de transformar um processo moroso em célere sem a observância da concentração dos atos processuais;

e) irrecorribilidade das decisões interlocutórias - consiste na obrigatoriedade de recorrer da decisão interlocutória juntamente com as questões de mérito. 
Em síntese, esses eram os elementos que compunham o modelo de processo adotado pelo CPC de 1939. Todavia, não se alcançou a celeridade e a eficiência pretendidas, sendo este o motivo da elaboração da lei processual vigente nos dias de hoje.

O legislador deixou claro na exposição de motivos que o "novo código" não iria adotar integralmente o modelo de processo oral até então vigente, textualmente: “[...] julgamos de bom aviso limitar o processo oral, não só no que toca ao princípio da identidade física do juiz, como também quanto à irrecorribilidade das decisões interlocutórias (MORATO, 1940, p.232)”.

Pode-se dizer que o Código de 1973 mitigou a oralidade processual perante a exclusão da irrecorribilidade das decisões interlocutórias e do princípio da identidade física do juiz. O direito processual do trabalho, todavia, não limitou o modelo de processo oral, pois o agravo de instrumento possui a finalidade de "destrancar" recurso cujo seguimento tenha sido denegado.

Magalhães (2011, p. 604) afirma que a vedação da recorribilidade das interlocutórias em separado constitui afronta aos princípios do contraditório e da ampla defesa. Tal argumento não pode prevalecer, porque a parte que se sentir prejudicada poderá recorrer dessa decisão juntamente com o mérito. Não se trata aqui de uma limitação ao contraditório e à ampla defesa, mas sim da aplicação equilibrada desses princípios com a finalidade de alcançar a celeridade processual.

Chiovenda descreve os seguintes benefícios decorrentes do modelo de processo oral:

a) redução de no mínimo dois terços dos atos judiciais; b) a Simplificação dos atos, pela sua concentração em audiência; c) Irrecorribilidade das decisões interlocutórias separadamente das questões de mérito; d) Resolução dos incidentes em audiência. Tais situações convertem-se em celeridade e menores custos (CHIOVENDA, 1940, p. 61).

Conclui-se que não basta a adoção da oralidade para alcançar-se a desejada celeridade. É de fundamental importância prestigiar a irrecorribilidade das decisões interlocutórias separadamente das questões de mérito. No Brasil, tem-se a experiência do direito processual do trabalho, que vem se mostrando extremamente eficaz. Em se tratando da tutela da saúde do trabalhador, a agilidade do provimento jurisdicional ganha relevância; e devem-se evitar ao máximo as dilações indevidas como forma de prestação da tutela jurisdicional tempestiva. 


\section{A TUTELA DE URGÊNCIA PREVENTIVA NO DIREITO DO TRABALHO}

Quando se estudam as tutelas ${ }^{6}$ de urgência no direito coletivo ou no direito individual, é necessária a utilização subsidiária do Código de Processo Civil em vigor, cujo artigo 300 definiu como requisitos a probabilidade do direito e o perigo de dano ou risco ao resultado útil do processo civil.

Antes de apontar o posicionamento dos processualistas acerca da probabilidade do direito e do perigo de dano ou risco ao resultado útil do processo, é conveniente destacar a crítica de Silva (2003, p. 141), que sustenta que seria mais adequada a utilização do periculum in mora no lugar de risco ao resultado útil do processo, tendo em vista que a categoria do periculum in mora é mais adequada à ideia de antecipação e "historicamente ligada às execuções provisórias".

$\mathrm{Na}$ sequência, apresenta-se o posicionamento de diversos autores acerca da interpretação do requisito do dano irreparável ou de difícil reparação.

\subsection{PERIGO DE DANO OU RISCO AO RESULTADO ÚTIL DO PROCESSO E PROBABILIDADE DO DIREITO}

O perigo de dano ou o risco ao resultado útil do processo consiste no fato de que o direito pode se extinguir de forma "inexorável" caso não haja uma proteção preventiva. Dessa forma, a demora do provimento pode atingir o objeto do processo, ou seja, torná-lo inútil. No tocante ao direito do trabalho, é possível citar os danos à saúde e à integridade física do trabalhador.

\footnotetext{
${ }^{6}$ Leal (2010, p.160) faz a seguinte observação acerca do significado da palavra tutela: "Em artigo publicado concluímos que, numa concepção de estado de Direito Democrático, não há que se falar em tutela, a não ser da lei de fonte popular, tornando-se, por isso mesmo, anacrônica a expressão tutela jurisdicional pela sentença que, no patamar da reflexão jurídica desse início de século, não pode mais ser entendida como ato de construção do direito, ou supletivo de direito não legislado. Assim, antecipar tutela não é antecipar sentença futura, mas aplicar por antecipação, os conteúdos tutelares da lei pelo ato sentencial interlocutório, se examinado o tema na perspectiva do que dispõe o artigo 273 do CPC vigente ante a teorização empreendida nos institutos da verossimilhança e inequivocidade em juízo lógico da existência de prova no procedimento como fundamento de convicção do juiz".
} 
Nesse contexto, a probabilidade do direito deve ser demonstrada no âmbito da estrutura procedimental, por meio de provas robustas e pertinentes a demonstrar a probabilidade do direito invocado pela parte.

Nesse sentido, parece razoável que esse requisito seja analisado em conjunto com o requisito da probabilidade do direito, sendo essa análise realizada em sede de cognição sumária. Assim, o juiz pode ser chamado a decidir em sede de liminar, ou seja, ainda não terá ocorrido o exaurimento dos confrontos entre os fatos e as alegações trazidas pela parte requerente.

Em sentido complementar, Assis (2001, p.60) assevera que "o órgão judiciário só deve expedir a liminar, conhecendo sumariamente se o direito alegado for passível de acolhimento em uma sentença futura".

Quando se trata do direito do trabalho, especificamente em relação à saúde e à integridade física do trabalhador, a tutela cautelar assume posição de destaque, tendo em vista o bem jurídico em questão. Por exemplo, ao conceder uma liminar com o intuito de paralisar uma atividade, ante a possibilidade de risco iminente à saúde dos trabalhadores, é necessário que a parte requerente anexe aos autos prova técnica capaz de convencer o magistrado do risco de dano irreparável a eles.

\subsection{LIMINAR SEM A OITIVA DA PARTE CONTRÁRIA}

A possibilidade de concessão da liminar sem a oitiva da parte contrária está presente no ordenamento jurídico desde o Regulamento n. 737 , de 1850 , ou seja, certamente é um dos institutos mais antigos do direito pátrio, o qual perdurou por todos os códigos de processo civil ao longo dos anos.

Todavia, o fato de a lei autorizar a concessão da tutela sem a audiência da parte contrária não quer dizer que o juiz deva adotar esse procedimento como regra (THEODORO JÚNIOR, 2001, p. 14).

Portanto, a concessão da liminar sem a audiência da parte contrária deve ser realizada apenas quando a oitiva do réu colaborar para a consumação do dano que se visa evitar (THEOTÔNIO NEGRÃO et al, 2010, p. 378). 
Em sede do direito do trabalho, o magistrado deve interpretar os dispositivos do Código de Processo Civil com a devida cautela, ou seja, deve deferir as medidas liminares preventivas quando houver informações minimamente comprovadas nos autos (CALDEIRA, 2006, p.190).

O posicionamento de Caldeira se coaduna com as peculiaridades do objeto deste trabalho, ou seja, por se tratar de bens jurídicos caros inclusive ao legislador constituinte, não seria razoável deixar de conceder a proteção cautelar diante de comprovações mínimas. Em sede de decisão, parece razoável que o magistrado observe quais são os bens jurídicos envolvidos (no caso, de um lado estão a atividade empresarial e o lucro e, de outro, a saúde e a integridade física do trabalhador).Nessas situações, portanto, o magistrado deve aplicar o in dubio pro misero.

\section{CONSIDERAÇÕES FINAIS}

Na elaboração deste artigo, verificou-se que o direito do trabalho está inserido no direito privado, ou seja, compete às sociedades empresárias, de forma concorrente com o Estado, atuar prevenindo a ocorrência de danos à saúde do trabalhador.

Constatou-se a importância da atuação do judiciário, cuja participação na proteção da saúde do trabalhador decorre da concessão de tutelas de urgência, com a finalidade de evitar prejuízos à saúde do trabalhador. Seguramente, grande parte das tutelas de urgência que possuem a finalidade de proteger a saúde e a vida do trabalhador será requerida sem a oitiva da parte contrária, porque nessas situações o transcorrer do tempo pode contribuir para a consumação do evento que se pretende evitar.

No tocante à conjugação entre a celeridade e a observância das garantias constitucionais do processo, concluiu-se pela constitucionalidade da liminar sem a oitiva da parte contrária como fator necessário para evitar o dano.

Ainda em relação à atuação do judiciário, verificou-se que a realização de termos de ajuste de condutas em algumas situações pode "legitimar" o dano à saúde do trabalhador, conforme narrado no termo de ajuste de conduta entre o Ministério Público do Trabalho e a fábrica de fogos de artifício de Santo Antônio do Monte. Parece razoável que, antes da celebração de tais termos, seja realizado um estudo técnico acerca dos riscos aos quais os trabalhadores estarão submetidos durante sua vigência. No caso em questão, talvez uma boa 
alternativa fosse a imposição de medidas com o objetivo de reduzir o risco à vida dos trabalhadores, como condição indispensável para a celebração do termo.

Em que pese o grande avanço ocorrido na defesa dos trabalhadores, ainda há um grande caminho a ser percorrido até que se chegue à proteção ideal.

Em relação à atuação do legislativo, sugere-se que sejam editados textos legais com o intuito de obrigar o empregador a eliminar o agente prejudicial à saúde do trabalhador, ou a adotar medidas que minimizem o risco. Sem dúvida, este é o ponto nevrálgico da questão, sendo necessário que o legislativo esteja imbuído da necessidade de proteção ao trabalhador, devido a sua hipossuficiência e, em muitos casos, diante da desídia do próprio sindicato.

Também seria de bom alvitre desestimular o trabalho em horas extras e em turno de revezamento para as atividades não essenciais. Na impossibilidade de se proibir o trabalho nessas condições, deveria ser imposto um rígido monitoramento da saúde do trabalhador, com caráter preventivo, com a finalidade de preservá-la. Por fim, outra medida interessante seria a majoração dos adicionais.

\section{REFERÊNCIAS}

ALMEIDA, Gregório Assagra de. Direito material coletivo: superação da summa divisio direito público e direito privado por uma nova summa divisio constitucionalizada. Belo Horizonte: Del Rey, 2008.

ANDOLINA, Ítalo. Il tempo e Il processo. Revista de Processo, São Paulo, ano 34, n. 176, out. 2009.

ANDRADE, Lourenço. Adicional de insalubridade como instrumento de monetização da saúde do trabalhador. Revista Síntese Trabalhista, v.15, n. 174, Porto Alegre: Síntese IOB, dez. 2003.

ASSIS, Araken de. Extinção do processo por superveniência do dano irreparável. Revista Direito e Justiça da Faculdade de Direito da Pontifícia Universidade Católica do Rio Grande do Sul, ano 23, v. 23, 2001.

BRASIL. Constituição da República Federativa do Brasil de 1988. Disponível em: <http://www.planalto.gov.br/ccivil_03/constituicao/constituicaocompilado.htm>. Acesso em: 25 jun. 2016.

CALDEIRA, Adriano. Aspectos processuais das demandas coletivas. São Paulo: Ridel, 2006.

CAMPOS, Francisco. A reforma processual. In: MORATO, Francisco et al. Processo oral: coletânea de estudos de juristas nacionais e estrangeiros. Rio de Janeiro: Revista Forense, 1940. 
CHIOVENDA, Giuseppe. Procedimento oral. Trad. Osvaldo Magnon. In: MORATO, Francisco et al. Processo oral: coletânea de estudos de juristas nacionais e estrangeiros. Rio de Janeiro: Revista Forense, 1940.

DELGADO, Maurício Godinho. Curso de direito do trabalho. São Paulo: LTR, 2006.

DIAS, Ronaldo Brêtas de Carvalho. Direito a jurisdição eficiente e garantia da razoável duração do processo no Estado Democrático de Direito. In: GALUPPO, Marcelo Campos (Org.). O Brasil que queremos: reflexões sobre o Estado Democrático de Direito. Belo Horizonte: Editora PUC/Minas, 2006, p.653-663.

DIAS, Ronaldo Brêtas de Carvalho. Processo constitucional e Estado Democrático de Direito. Belo Horizonte: Del Rey, 2010.

GRINOVER, Ada Pellegrini. Os princípios constitucionais e o código de processo civil. São Paulo: Bushatsky, 1975.

GUIMARÃES, Luís Machado. O processo oral e o processo escrito. In: MORATO, Francisco et al. Processo oral: coletânea de estudos de juristas nacionais e estrangeiros. Rio de Janeiro: Revista Forense, 1940.

LEAL, Rosemiro Pereira. Processo como teoria da lei democrática. Rio de Janeiro: Fórum, 2010.

LEITE, Carlos Henrique Bezerra. Curso de direito processual do trabalho. 7. ed. São Paulo: LTR, 2009.

MACIEL JÚNIOR, Vicente de Paula. Proteção à saúde do trabalhador. Revista da Faculdade Mineira de Direito, v.1., n. 1, Belo Horizonte: PUC Minas. jan./jun. 1998.

MACIEL JÚNIOR, Vicente de Paula. Audiência pública realizada no Tribunal Regional do Trabalho da Terceira Região, no dia 14 de novembro de 2011.

MACIEL JÚNIOR, Vicente de Paula. Tutelas de urgência satisfativas X execução provisória: contradições de um CPC retalhado. Artigo disponibilizado pelo autor ainda não concluído, 2012.

MAGALHÃES, Joseli Lima. A irrecorribilidade das decisões interlocutórias. In: LEAL, Rosemiro Pereira; ALMEIDA, Andréa Alves de (Coord.). Comentários críticos a exposição de motivos do CPC de 1973 e os motivos para a elaboração de um novo CPC. Franca: Lemos \& Cruz, 2011.

MARINONI, Luiz Guilherme. Novas linhas do processo civil. São Paulo: Malheiros, 1996.

MORATO, Francisco. A oralidade. In: MORATO, Francisco et al. Processo oral: coletânea de estudos de juristas nacionais e estrangeiros. Rio de Janeiro: Revista Forense, 1940. 
OLIVEIRA, Sebastião Geraldo de. Proteção jurídica à saúde do trabalhador. 6. ed. rev. atual. São Paulo: LTR, 2011.

SERBENA, César Antônio. Considerações sobre o juiz, a sentença e a tutela preventiva na história do processo civil. Revista da Faculdade de Direito da Universidade do Paraná, Curitiba, 2004, n.1.

SILVA, Ovídio A. Baptista da. Curso de direito processual civil. 6. ed. rev. e atual. São Paulo: Revista dos Tribunais, 2003. v. 1.

THEODORO JÚNIOR, Humberto. Tutela jurisdicional de urgência: medidas cautelares e antecipatórias. Rio de Janeiro: América Jurídica, 2001.

THEODORO JÚNIOR, Humberto. Curso de direito processual civil. 46. ed. rev. e atual. Rio de Janeiro: Forense, 2011. v. II.

THEOTÔNIO NEGRÃO et al. Código de Processo Civil comentado. São Paulo: Saraiva, 2010. 